\title{
NCAA Exit Interviews and Surveys: Academic Experiences of College Athletes
}

\author{
Molly Harry \\ University of Virginia
}

\begin{abstract}
Institutions are required to conduct exit interviews and surveys (EIS) with departing athletes, however, these instruments are currently an untapped data source for further understanding the college athlete experience. Through the lens of Comeaux and Harrison's conceptual model for student-athlete academic success, this study examined 17 FBS institutions' exit interviews and surveys with 528 athletes, focusing on athletes' academic experiences. Analyses revealed that EIS questions pertaining to educational experiences focused on the following areas surrounding athletic/institutional environment and academic outputs: academic services, overall academic experiences, time demands, coach support of academics, and faculty support. Athletes in this sample expressed overall positive academic experiences and gratitude for the academic services provided. Additionally, the majority of athletes noted few issues with time demands, strong coach support, and positive faculty interactions. These findings challenge some of the current literature noting negative educational experiences and opportunities for college athletes. Implications and recommendations are discussed.
\end{abstract}

Keywords: exit interviews, exit surveys, intercollegiate athletics, academics

\section{Introduction}

According to Article 6.3 of the NCAA's Division I Manual, member institutions are required to conduct end-of-year exit interviews or surveys with departing athletes (NCAA Manual, 2019). These interviews are conducted by the athletic director, senior woman administrator (SWA) or another representative (excluding coaches and team staff members). Interviews must be performed with each sport, but the sample of athletes selected is determined by the institution (NCAA Manual, 2019). The only factor institutions must consider when selecting athletes is that their athletic eligibility has expired. Having completed eligibility may result in less retaliation and allows for athletes to provide feedback and express their opinions more honestly. However, some athletes may still be apprehensive about such processes and potential retaliation if they wish to take advantage of sport connections and opportunities upon graduation, such as graduate assistant positions (Hermandorfer, 2014; Johns \& Gorrick, 2016). 
Despite the vagueness of the rule and the lack of uniformity across the NCAA when it comes to exit interview and survey implementation, bylaw 6.3 provides a positive outlet for athletes to share their experiences and be heard by campus leaders. Similarly, these documents present a unique opportunity to appreciate the athlete voice in evaluating how athletics operates. Data collected from the exit interviews and surveys are used to evaluate athletics programs and are examined by athletic directors, university presidents, coaches, faculty athletics representatives, and others. Information may be used to determine how teams and the department as a whole are serving their athletes (NCAA Manual, 2019). However, few researchers and practitioners have access to such information, thus, not much is known about what athletes discuss in these settings. Similarly, little is known due to the often-sensitive nature of subjects discussed (Gordon, 2011, 2014).

Exit interviews and surveys are currently an under-explored area in the intercollegiate athletics literature. Football Bowl Subdivision (FBS) exit interview and survey data for this study was gathered from The Intercollegiate, a public-service journalism platform that critically examines college athletics. Through the lens of Comeaux and Harrison's (2011) model for student-athlete academic success, this study examined 528 athletes from 17 programs to explore educational experiences and highlight athlete voices. Many scholars note the increasing commercialization of collegiate athletics and the decreasing focus on academics (Clotfelter, 2019 Gurney et al., 2017; Lumpkin, 2017). The prioritization of sports over education influences athletes' experiences and potentially minimizes their voices, especially when it comes to academics. Additionally, while the NCAA requires athletic departments to conduct exit interviews and surveys, some departments may just be checking a box and fulfilling a requirement, without placing much intentionality and care into understanding the experiences of their athletes (Libit, 2020).

However, it is crucial to understand how college athletes and their academic experiences are impacted by this commercialization process in order to make meaningful improvements in this field and enhance their time in college (Lumpkin, 2017). Analysis of exit interviews and surveys provide a unique avenue for this endeavor. Particular attention was given to academics, as scholars have noted that education tends to take a backseat in the college athletics model (Gurney et al., 2017; Hirko \& Sweitzer, 2015; Lumpkin, 2017), so, a deeper analysis of athletes' academic experiences is warranted. With this in mind, the purpose of this study was to explore the athlete academic experience through the voices of athlete participants themselves so athletic departments can capitalize on these narratives and improve their exit interviews and surveys and athletes' experiences as students. As such, the following research questions were addressed: (1) what academic topics are discussed in exit interviews and surveys; and (2) what do college athletes say about their academic experiences?

\section{Literature Review}

This literature review discusses two important areas, beginning with the origins and purpose of exit interviews and surveys. The next section examines the current 
literature on academic experiences of college athletes, paying particular focus to admissions, time demands, stereotypes, pressures to remain eligible, and academic support.

\section{Exit Interviews and Surveys}

Originating in the business industry, exit interviews and surveys (EIS) are an exchange of information between a departing employee and a representative of an organization (Buhler, 2011; Gordon, 2014). The purpose of EIS is to gain information about how an employee feels about the company environment, compensation and benefits, professional development, and relationships with co-workers (Gordon, 2014). Questions asked and topics discussed may vary from one organization to another, but regardless of the questions and topics, if used appropriately, the data provided can ensure organizations are achieving goals while maintaining employee satisfaction. In fact, over $91 \%$ of Fortune 500 companies collect EIS data and use it to improve culture and retention (Zojceska, 2018). Once organizations have collected data from EIS, interventions can be adapted to make advancements, or new policies can be implemented (Johns \& Gorrick, 2016).

Scholars (Gordon, 2011; Hargie, 2006) emphasize the importance of contact and structure of EIS protocols. For example, contact with the departing employee during EIS should be made by a third, neutral party outside of the organization, but someone with experience in EIS (Johns \& Gorrick, 2016). Branham (2005) examined how multiple companies experiencing high turnover were able to shift their practices and maintain their most critical workers. One method these companies used was EIS conducted by a third party, which allowed for employees to feel comfortable in expressing their reasons for leaving.

Despite the host of benefits EIS offer organizations, there are a few critiques to the process (Gordon, 2014). Administrative critiques stem mostly from practitioners, as organizations rarely use the information garnered from EIS to implement improvements. The methodological critique argues that techniques used to conduct EIS are fundamentally flawed, and thus, lack reliability and validity (Gordon, 2014; Schmitt, 2014; Williams et al., 2008). Due to the underlying deficiencies of the methods, the results obtained from EIS may be biased and inaccurately represent the departing employees' experiences. In examining the EIS process of a large publishing company, Johns and Gorrick (2016) found that departing employees were reluctant to offer their true reasons for leaving the company and did not want to negatively influence the work environment of their remaining colleagues or "burn any bridges" in case they needed a reference letter or wanted to collaborate in the future ( $\mathrm{p}$. 10). Additionally, some were concerned with how their private information would be handled. Thus, they offered less controversial responses to the EIS questions. However, most of the employees in the study still found the EIS process an effective avenue to offer constructive feedback.

In spite of these criticisms, exit interviews and surveys have been adopted by various other fields including intercollegiate athletics. Since 1991, the NCAA has required institutions to conduct EIS with departing athletes who have exhausted their 
eligibility (NCAA Manual, 2019). Athletic EIS are conducted with an institutional or athletic department self-selected sample of athletes from each sport and are administered by an athletic department representative such as a faculty athletics representative (FAR) or senior woman administrator (SWA). There is no uniform NCAA EIS protocol, so institutions are at liberty to create their own questions and practices. While this enables flexibility for schools to address specifics related to their own programs, it hinders cross-comparison in experiences between NCAA divisions, conferences, and institutions.

Additionally, during their collegiate careers, athletes may be silenced or encouraged not to speak out when they have concerns for fear of repercussions, such as loss of scholarship status or playing time (Benedict \& Keteyian, 2014; Hawkins et al., 2015). Implementation of EIS in athletics is important because it provides athletes an outlet to discuss and share their academic, athletic, and social experiences. For example, in 2017 results from EIS at Syracuse University noted that athletes experienced racially insensitive remarks from their coaches and were forced into majors they did not want (Burke, 2017). Based on the narratives of the athletes in this EIS, the Faculty Oversight Committee was able to make suggestions to the athletic director, such as reminding coaches to be more racially sensitive and providing better advising about major options (Faculty Oversight Committee Annual Report, 2017). More recently, in the process of requesting EIS, members of The Intercollegiate uncovered accusations of coach abuse within Texas Tech University's women's basketball team (Libit, 2020). Prior to uncovering these documents and making them public, these athletes' voices were silenced as they continued to compete under their coach (Libit, 2020). As a result of this exposure, the coach was terminated and Texas Tech has released statements supporting their athletes and noting they will take action to improve athletes' experiences at the institution (Epstein, 2020).

Both of the above examples highlight the importance of EIS documents as a data source and their ability to enhance the athlete experience. However, limited research has explored the nexus of athletics and EIS and little is understood about what departing athletes say about their collegiate experiences. This limits the importance of the athlete voice in intercollegiate athletics, prevents important research from being conducted, and hinders the ability to enhance athletes' experiences as students. This study fills this current literature gap by (1) exploring athlete EIS by honing in on athletes' academic experiences and (2) elevating the athlete voice.

\section{Academic Experiences of College Athletes}

\section{College Entrance}

Prior to enrollment in college, athletes are required to meet NCAA academic conditions and be cleared by the NCAA Eligibility Center. These conditions include enrolling in certain core courses, maintaining a minimum 2.3 grade point average (GPA) in these courses, and receiving minimum scores on standardized tests (Play Division I Sports, n.d.). These minimums are under scrutiny as some athletes are specially admitted and not held to similar entrance standards as non-athletes (Hendricks 
\& Johnson, 2016). Thus, some athletes come to campus underprepared for the rigors of college courses (Rubin \& Moses, 2017; Smith \& Willingham, 2015). This lack of preparation for college can pose potential problems once athletes are enrolled, however, athletes are capable of having beneficial educational experiences. Knowing more about what athletes say regarding their academic experiences through EIS aids in understanding their experiences.

\section{Time Demands}

At the heart of academic experiences are time demands, or the equilibrium athletes find concerning their obligations, requirements, and opportunities pertaining to athletics and academics (Gayles, 2015). The NCAA mandates that college athletes spend no more than 20 hours per week on their sport (NCAA Manual, 2019). However, in the most recent NCAA GOALS study, athletes self-reported spending upwards of 34 hours per week on their sport-related activities, along with 38.5 hours on their academics (NCAA GOALS, 2016). Research on time demands demonstrates that finding and maintaining a balance between sport and school is moderately challenging for Division I athletes (Di Lu et al., 2018). Time demands may also make the athlete experience distinct from their counterparts not participating in intercollegiate sport. In their seminal piece, Potuto and O'Hanlon (2007) surveyed 2,335 athletes at Division I schools and compared their results to non-athletes from the National Survey of Student Engagement (NSSE). Only 36\% of athletes reported participating in curriculars outside of sports, while $52 \%$ of non-athletes reported involvement in curriculars. More recently, a time demands study of Pacific 12 Conference athletes noted that $70 \%$ of participants voiced an interest in participating in a study abroad or internship program but were unable to due to athletic time demands (Penn Schoen Berland, 2016). Still, some athletes do not report issues with time demands and others even report that they wish to spend more time on sports (NCAA GOALS, 2016; Penn Schoen Berland, 2016). More research is needed to examine the relationship between academic experiences and athlete time demands.

\section{Faculty Interactions}

Some faculty maintain the "dumb jock" stereotype of college athletes, which holds that athletes only enroll in college to play their sport and are less capable than their non-athlete peers (Wininger \& White, 2008). Research also demonstrates that faculty hold more prejudicial attitudes toward athletes than non-athletes (Engstrom et al., 1995). Comeaux (2011b) employed an adapted situational attitude scale (SAS) for athletes to examine 464 faculty members perceptions of non-athletes and athletes at a Division I institution. The scale asked faculty to rate their feelings toward non-athletes and athletes in various hypothetical scenarios such as receiving an A in their class, being admitting with lower standardized scores, and receiving a scholarship. Results indicated that faculty held more prejudicial views of athletes. For example, when compared to non-athletes, faculty thought it unexpected and impossible for an athlete to receive an $\mathrm{A}$ in their class. Additionally, scenarios in which athletes were successful elicited feelings of suspicion and resentment. Importantly, not all athletes 
report poor experiences with faculty. However, some athlete groups, particularly those in the revenue-generating sports of men's basketball and football, or those who are athletes of color, may have more negative academic experiences than athletes in non-revenue sports or those who are members of dominant racial groups (Comeaux, 2011a, 2011b; Singer, 2015, 2019).

These negative stereotypes influence academic performance: heightening an athlete's athletic identity via stereotypical perceptions increases their vulnerability to the dumb jock narrative, which then negatively influences their academic experiences (Stone et al., 2012; Yopyk \& Prentice, 2005). In spite of this potential obstacle, many athletes report positive academic experiences (Penn Schoen Berland, 2016) and $66 \%$ of athletes report a strong relationship with at least one faculty member (NCAA GOALS, 2016). More research is necessary to flesh out faculty-athlete relationships.

\section{Athlete Pressures}

The pressure to remain eligible or focus solely on athletics is also part of the athlete academic experience (Gayles, 2015), with this insistence potentially coming from coaches and academic advisors (Horner et al., 2016; Jayakumar \& Comeaux, 2016; Rubin \& Moses, 2017). Some scholars believe that commercialization resulting in increased pressure and win-at-all-costs mentalities in athletics has led to an increase in a focus on eligibility over education and academic misconduct, such as the decades-long scandal at the University of North Carolina at Chapel Hill (Gurney et al., 2017; Ridpath, 2010; Smith \& Willingham, 2015). For example, former UNC-Chapel Hill basketball star Rashad McCants spoke out against his former institution, explaining that he was steered toward easier classes to maintain his eligibility (Carolina Alumni Review, 2014). When asked about the courses he was enrolled in during an interview with $E S P N$, McCants said,

I thought it was part of the college experience... You're not there to get an education, though they tell you that. You're there to make revenue for the college. You're there to put fans in the seats. You're there to bring prestige to the university by winning games (Carolina Alumni Review, 2014).

Coaches play a significant role in the lives of athletes and can influence the energy players dedicate to academics (Hawkins et al, 2015; Horner et al., 2016). While coaches may stress the importance of receiving an education during the recruiting process, this emphasis tends to decline once the athlete enrolls at the institution and begins competing (Jayakumar \& Comeaux, 2016). Some scholars note that this results in a "compromised version" of academics (Jayakumar \& Comeaux, 2016, p. $502)$ and the overall "miseducation" of college athletes, particularly athletes of color (Shropshire \& Williams, 2017; Singer, 2015, 2019).

Coaches who are supportive have athletes who perform well across environments, including on the courts and in classrooms (Jowett, 2017). However, limited research exists on positive athlete-coach dyads and the influence this relationship has 
on educational experiences. Thus, further examining the experiences athletes have with their coaches concerning academics is crucial to not only better understanding these situations, but also to improving the academic opportunities of college athletes.

\section{Academic Support Programs}

In 1991, the NCAA required institutions to provide academic support services for athletes and since then, these programs have become a popular topic of research and media attention. Athletic academic support programs provide advisors for athletes, tutoring, study hall areas, mentorship, and a host of other resources. These centers have coincided with an increase in athlete retention and graduation, thus, clearly influencing the athlete academic experience (Huml et al., 2014). Ridpath (2010) noted that athletes expressed a need and usefulness regarding the resources provided by academic support programs. However, he also found an over-reliance by revenue-generating athletes on the use of these resources to remain eligible rather than taking advantage of a college education (Ridpath, 2010). This is backed by research from other scholars noting that academic support programs are now commonly viewed and used as an avenue to merely maintain eligibility. In a study by Huml and colleagues (2014) some athletes found the support center to be a hindrance to their academic development because the building was isolated from other areas of campus and made it more challenging to develop relationships with faculty and others outside of the athletic community.

Despite the aforementioned concerns, over $75 \%$ of college athletes report positive overall academic experiences during their time in college (NCAA GOALS, 2016). The current scholarship discussed offers insight into the athlete academic experience, however, this literature has yet to tap into athlete EIS to directly appreciate the athletes discuss their experiences.

\section{Conceptual Framework}

Athlete EIS were examined through the lens of Comeaux and Harrison's (2011) conceptual model of academic success for student-athletes. While most higher education conceptual models are built to understand and explain the traditional student population, Comeaux and Harrison's (2011) model is tailored toward college athletes, making it an appropriate framework for this research. The model is inclusive of cumulative processes and factors that help explain the academic experiences of athletes, including precollege characteristics and initial commitments, social and academic systems and integration, commitments post-integration, and academic success (Comeaux \& Harrison, 2011). Based on limitations in the data collected via EIS and the reflective nature of the EIS process, this study focuses on the athlete environment, including social and academic systems and academic integration, along with outputs including post-integration commitments and academic success.

An athlete's social system includes faculty and peer interactions, the Scholar-Baller paradigm, coach demands, and sport participation. The academic system encompasses grades, intellectual development, and the Scholar-Baller paradigm 
(Comeaux \& Harrison, 2011). While these are distinct systems, the two interplay and influence one another. For example, stringent demands from a coach (social system) to focus more on athletics, could impact an athlete's ability to perform well in the classroom or develop intellectually (academic system). Additionally, the Scholar-Baller paradigm was established by Harrison and Boyd (2007) to improve athlete academic success and integration and was designed for academic support services, highlighting the importance of these programs for college athletes. The above systems and their components are areas discussed in athletic EIS.

Social and academic integration, such as the ability to meet faculty in office hours and confidence in one's academic capabilities, are crucial in producing commitments to one's goals, sport, and institution (Comeaux \& Harrison, 2011). Goal commitments may include an athlete's plan to pursue graduate school, making an athlete more likely to matriculate (Comeaux \& Harrison, 2011; Tinto, 1975). The psychological and physical time and energy spent on sport is one's sport commitment, while academic commitment encompasses the feelings an athlete holds toward their institution and the importance assigned to degree attainment (Tinto, 1975). As athletes reflect on their college experience in EIS, commitments are a likely topic of discussion.

Finally, the above culminate in and help explain the athlete's academic success or failure. Using Comeaux and Harrison's (2011) conceptual model to examine athletic EIS can assist practitioners and scholars in better understanding athletes' experiences and the various processes and factors that go into academic success. As athletes reflect on these in EIS, this information can be used to enact important changes or improvements to the social and academic systems, integration and commitments, and ultimately academic success.

\section{Method}

\section{Materials}

There are various platforms used for athletic EIS and documents from The Intercollegiate were selected. This EIS outlet serves as an active research collaborator with scholars while critically studying college athletics and makes the data collected public unlike other platforms. The public availability is particularly important as it enhances transparency, credibility, and dependability of both the data obtained by the platform and the results of this study (Nowell et al., 2017). The Intercollegiate filed formal records requests with every Division I institution subject to public disclosure laws for 2018-2019 EIS documents (Exit Interviews, n.d.). The Intercollegiate notes that many institutions denied these requests, citing privacy laws or exemptions in disclosure of public records. While some institutions provided EIS data, others offered only their questions or blank forms without athlete responses. Additionally, some schools included end-of-season interviews or surveys and those are not included in this study as these instruments are different from measures used in EIS and could have varying results as many athletes in end-of-season analyses must return to 
their institution and may not be as honest in their responses. Still, the EIS information provides great insight into the academic experiences of athletes. One hundred and twenty-one institutions complied with the requests, but only 63 offered athlete responses. Of those, 17 were in the FBS and constitute the sample in this study.

The EIS in this sample included surveys filled out by the athletes themselves ( $n$ $=9$ schools) and interview documents in which athlete responses were recorded by a representative ( $n=8$ schools). Additionally, 6 institutions resided in the Power Five (P5): the Atlantic Coast Conference (1), Big Ten (1), Big 12 (2), Pac-12 (1), and the Southeastern Conference (1). Eleven institutions came from four conferences outside of the P5: Conference USA (3), Mid-American Conference (3), Mountain West Conference (3), and the Western Athletic Conference (2). The EIS in this sample ranged in style of questions, such as Likert scale, yes/no, and open-ended and topics.

It is important to note that the internal validity of these documents has not been addressed by The Intercollegiate or the researcher. It is unknown, for example, if the representatives interviewing the athletes performed member checking by returning their session notes to athletes to corroborate findings. Additionally, the validity of the responses requires some assumptions. The first assumption is that the athletes participating in the EIS answered the questions honestly. The second assumption is that for EIS that were recorded by a representative rather than the athletes themselves, the representative accurately and truthfully represented the answers athletes provided. Thus, the EIS documents only reflect the insight provided by the athletes to their institutions. However, because this data set is available to the public and other researchers, reliability of this research is maintained (Merriam, 2002; Nowell et al., 2017).

\section{Participants}

Participants in this study included collegiate athletes selected by their institutions to complete EIS, and who had exhausted their athletic eligibility at their institution by the end of the 2019 academic year $(n=528)$. Twenty-four percent $(n=127)$ were athletes in the P5, while the remaining 76\% $(n=401)$ came from athletes competing outside the P5. The anonymity of the participants was maintained by the institutions when they responded to the information request, by The Intercollegiate via additional redactions, and by the researcher who did not make attempts to discover or disclose the identity of the participants. To further protect athlete identity, institutional names are not included with later narratives.

Due to these safeguards, little demographic information is available about the athletes in this sample. Thus, race, ethnicity, sex, and sport are largely unknown. However, because the athletes have completed their eligibility at their institution, it is likely that the age range of the sample falls between 21 and 23 years old. Additionally, pre-college characteristics of these athletes are also unknown and outside the scope of the EIS and this research. However, a detailed description of the analyses is provided below to ensure credibility and dependability of the study (Lincoln \& Guba, 1985; Nowell et al., 2017). 


\section{Analyses}

As suggested by Nowell and colleagues (2017) the five phases of thematic analysis pre-publication were followed to assist in establishing trustworthiness of this study. In phase one, the author became familiar with the data and documented theoretical thoughts and notes about potential codes and themes. Upon completion of reviewing the EIS, the author employed a deductive approach based on Comeaux and Harrison's (2011) conceptual model of academic success for student-athletes and re-examined the data (Miles et al., 2020). Here, phases two through five were initiated, which included coding, theming, reviewing the themes, and finalizing the themes (Nowell et al., 2017).

Document analysis was performed on the EIS to gather the academic topics discussed that related to the social and academic systems, integration, commitments, and academic success presented in the conceptual model (Brown, 2009; Brey, 2018), which assisted in answering RQ1. A priori coding was employed based on Comeaux and Harrison's (2011) work for common questions and topics pertaining to athlete's academic experiences. Descriptive first cycle a priori coding to second cycle pattern coding (Miles et al., 2020; Saldana, 2016) was performed to summarize the codes into a number of smaller categories which resulted in the following themes from EIS: overall academic experience, academic support services, coaches' support of academics, interactions with faculty, and time demands.

Next, athlete responses to these questions were examined to address RQ2. For example, some institutions asked athletes to rate their overall academic experience on a scale of 1 to 10 . Here, frequency in ratings were used to offer a more descriptive analysis of answers to these questions, which allowed for patterns in athlete academic experiences to emerge (Lofland et al., 2006). For more open-ended questions, concept coding and NVivo coding were coupled to organize athlete narratives into macrolevels of meaning, which provided "bigger picture" analyses that could then be organized by repeated themes (Miles et al., 2020). This method allowed for participants' narratives to be condensed into themes while also retaining their voices (Saldana, 2016).

\section{Results}

\section{Instrument \& Content [RQ1]}

The most common question topic in this sample of EIS pertained to academic services offered by the athletic department. Some sub-topics in this area included discussing the quality of the advising, experiences with tutors and study hall, and potential resource improvement. These questions tended to be open-ended allowing for athletes to elaborate on their response or closed-ended Likert questions that involved rating received services (i.e., "on a scale of one to ten rate your experience with academic support").

The next most frequent question topics included those about academic experiences and time demands. Questions related to both of these topics ranged in style. While some institutions preferred closed-ended Likert-style questions (i.e., "rate 
your overall academic experience"), others asked open-ended questions on these topics (i.e., "did you have a good experience academically?"). The final two topics covered by EIS questions pertained to the academic support of coaches and faculty support.

In keeping with the above results, the majority of athletic departments ( $n=16$, 94\%) asked questions about academic services. Table 1 details the frequency with which the schools in this sample asked questions related to the remaining topics: academic experiences, time demands, coach academic support, faculty support, and other. Topics discussed in the other category include general improvements to academics and major steering.

Table 1

Academic Questions Asked of Exiting Athletes

\begin{tabular}{lcc}
\hline Topic & Number of Departments & $\%$ \\
\hline Academic Services & 16 & $94 \%$ \\
Academic Experience & 14 & $82 \%$ \\
Time Demands & 11 & $65 \%$ \\
Coach Academic Support & 8 & $47 \%$ \\
Faculty Support & 3 & $18 \%$ \\
Other & 3 & $18 \%$ \\
\hline Total Athletic Departments & 17 & $100 \%$ \\
\hline
\end{tabular}

\section{Athlete Experiences [RQ2]}

Overall, athletes in this sample indicated that they enjoyed their collegiate academic experiences (see Table 2). Of the 144 athletes who answered questions about this topic, $96 \%(n=138)$ expressed having a good or excellent academic experience. One athlete said, "I love this school and its traditions. As a student the classes are difficult, but to say I got my degree from here is really exciting." Another respondent added, "I loved it. Going to school and playing was difficult, but it was the best four years of my life." The remaining 4\% $(n=6)$ stated that their experience was average, and no athlete discussed having a poor experience academically.

Of the entire sample of 528 athletes, $437(83 \%)$ answered questions about athletic-academic support services. Almost ninety-percent of athletes found the academic support services (i.e., advisors, tutors, mentors, etc.) to be of good $(n=212,49 \%)$ or excellent quality $(n=180,40 \%)$. One athlete who felt strongly supported stated: "This environment is hands down the most supportive environment I have ever been in." An athletic representative noted that an athlete she interviewed said her advisor advocated for her when she had a conflict with academic and athletic demands. A 
Table 2

Athlete Responses to Academic Experiences

\begin{tabular}{|c|c|c|c|c|c|c|c|c|}
\hline \multirow[b]{2}{*}{ Rating } & \multicolumn{2}{|c|}{$\begin{array}{l}\text { Academic } \\
\text { Services }\end{array}$} & \multicolumn{2}{|c|}{$\begin{array}{c}\text { Coach Academic } \\
\text { Support }\end{array}$} & \multicolumn{2}{|c|}{$\begin{array}{l}\text { Faculty } \\
\text { Support }\end{array}$} & \multicolumn{2}{|c|}{$\begin{array}{l}\text { Overall Academic } \\
\text { Experience }\end{array}$} \\
\hline & $n$ & $\%$ & $n$ & $\%$ & $n$ & $\%$ & $n$ & $\%$ \\
\hline Excellent & 180 & $41 \%$ & 170 & $44 \%$ & 53 & $33 \%$ & 86 & $60 \%$ \\
\hline Good & 212 & $49 \%$ & 141 & $36 \%$ & 75 & $47 \%$ & 52 & $36 \%$ \\
\hline Average/Neutral & 28 & $6 \%$ & 46 & $12 \%$ & 21 & $13 \%$ & 6 & $4 \%$ \\
\hline Poor & 17 & $4 \%$ & 33 & $8 \%$ & 10 & $6 \%$ & 0 & $0 \%$ \\
\hline Total & 437 & $100 \%$ & 390 & $100 \%$ & 159 & $100 \%$ & 144 & $100 \%$ \\
\hline
\end{tabular}

few athletes in the sample $(n=17,4 \%)$ did express poor experiences with academic support. For example, one athlete mentioned that their experience was frustrating because they felt advisors were "putting athletes in classes just to stay eligible." Additionally, athletes in this category also discussed how limited the resources were for athletes in majors that were considered more rigorous and how the study hall area was not conducive to learning and suggested making it "less of a social environment."

Athletes were also asked about their experiences with time demands (see Table 3 ). The most common question in this category involved whether athletes missed class for practice or competitions. Eighty-five percent of athletes explicitly stated they had not missed class for practice or competitions, while $9 \%$ said that they had foregone attending class for a sports-related activity. Additionally, $6 \%(n=20)$ of athletes said that their athletic time demands hindered their ability to enroll in certain majors or take classes. One athlete stated, that they wanted to enroll in their institution's computer science program, but "most of the computer sciences classes are during practice." Another added,

I had extra outside work assignments for classes such as interviews, site visits, meet and greets and I always felt conflicted with having to make a choice on missing these activities or attend practice. Even with ample warning time for said events, I would still feel both conflicted and often yelled at for having put my education first.

The time demands literature notes the struggles of many athletes to balance academics. However, 151 (42\%) athletes mentioned that their demands were excellent, good, or that they did not have issues. For example, when one athlete was asked, "was your practice/competition schedule ever a hindrance to you academically," they replied, "no, academics were always a top priority. We are STUDENT-athletes." Another athlete voiced, "time demands were really good. Allotted time for practice is sufficient and class always comes first." 
Thirty-eight athletes in this sample (11\%) believed their time demands were poor or struggled to find an equilibrium between the various demands of their school and sport obligations. One athlete mentioned there was "no balance" and another discussed issues with the demands: "I was not prepared enough for how difficult the time expectations of being a student-athlete were going to be. I do not know, though, if there is any amount of teaching or preparation that can get you ready for that." Still, others noted that being an athlete was "like having a part-time job."

Academic support from head coaches and faculty were also discussed throughout the EIS in this sample. Of the athletes who discussed these topics, $80 \%(n=$ 311) believed their head coaches offered good or excellent support of their academic pursuits. One athlete voiced, "coaches in our program were very understanding when it came to classes and school and want us to be the best students we can be." Other athletes noted that their coaches would let them leave practice early or skip weekend competitions to keep up their grades. One such athlete discussed that his coach "understands you have a life more than just football." Additionally, $80 \%(n=128)$ of the athletes asked about faculty support found professors to be helpful and positive during their academic careers.

Table 3

Athlete Responses to Time Demands

\begin{tabular}{lcc}
\hline Category & $n$ & $\%$ \\
\hline Excellent & 52 & $14 \%$ \\
Good & 71 & $20 \%$ \\
Neutral/"No Issues" & 58 & $16 \%$ \\
Bad & 18 & $5 \%$ \\
Time Management is Key & 25 & $7 \%$ \\
Need a More Consistent Schedule & 24 & $7 \%$ \\
Struggled to Balance Demands & 20 & $6 \%$ \\
Hindered Ability to Enroll in Classes & 20 & $6 \%$ \\
Demands Come with being an Athlete & 18 & $5 \%$ \\
Adjusted to the Demands & 17 & $5 \%$ \\
\hline Total & 360 & \\
\hline
\end{tabular}

Note. Total reflects the number of athletes who answered questions pertaining to time demands. Athletes may have offered responses that fell in multiple categories above; thus, the total percentage does not add up to $100 \%$. 
When analyzing these findings two items are important to note: athletes in this sample were not necessarily asked about all of the topics discussed (i.e., some athletes may have just answered a question about their overall academic experience and nothing else) and some of the questions posed inquired about multiple topics (i.e., double-barreled questions), thus one question could have one or multiple codes.

\section{Discussion}

The purpose of this study was to improve understanding of the athlete academic experience, while simultaneously elevating the athlete voice in these experiences. To achieve this purpose, this research addressed the following two questions: (1) what academic topics do athletic departments ask their athletes; and (2) what do college athletes say about their academic experiences? This study explored the academic experiences of 528 departing athletes across 17 different FBS institutions, adding a unique contribution to the current literature on intercollegiate sports. These EIS and the athletes' voices within them offer practitioners in athletics and higher education the opportunity to not only better understand the athlete academic experience, but also the ability to capitalize on what is said to improve the experiences of the next generation of athletes, thus providing support for the utility of these processes in intercollegiate athletics. The remainder of this section discusses the topics and styles of questions asked during athletic EIS followed by an examination of athlete responses. Implications and recommendations for the field are provided.

\section{Instrument \& Content}

The topics and design of the questions asked demonstrate where institutions and athletic departments place their attention and what they deem important. In total, the 17 institutions in this sample asked 637 questions across varying topics. Of these, only 90 or $14 \%$ pertained to academics, which may suggest that these schools did not emphasize or believe academics to be a critical component to their athletes' collegiate experiences, supporting prior scholarship noting the emphasis on revenue generation and commercialization over education (Lumpkin, 2017). Additionally, if they are student-athletes, one might expect more EIS questions pertaining to their student role. Satterfield, Croft, and Godfrey (2010) agree with this, highlighting the fact that athlete academic experiences and success "should be shared between the athlete and the university in general because of the student label, and specifically on the athletic department because of the athlete label"' (p. 2). So, as institutions and athletic departments continue to take on some responsibility for providing appropriate academic opportunities for their athletes, Comeaux and Harrison's (2011) conceptual model can be used as a guide to not only mold these experiences, but also inquire about them in EIS.

The most common academic topic discussed during EIS regarded academic services, such as experiences with and helpfulness of advisors, the quality of tutoring and study hall, and other academic resources such as mentorship programs and computer labs, which are critical components to the academic systemic discussed by 
Comeaux and Harrison (2011). The NCAA has increased its emphasis on academics (Division I Academic Progress Rate, n.d.), so athletic departments and institutions continue to allocate more money and resources to athletes and programs supporting them (Huml et al., 2014; Knight Commission, 2014). Additionally, recent academic-athletic scandals, such as those at UNC-Chapel Hill and the University of Missouri in which staff over-assisted athletes, demonstrate a need to pay closer attention to academic support programs (Lederman, 2019; Smith \& Willingham, 2015). Thus, it is unsurprising that the majority of academic questions pertained to these services.

The next topics most frequently discussed were those pertaining to overall academic experience and time demands, composing parts of athletes' academic and social systems, respectively (Comeaux \& Harrison, 2011). The majority of questions about these topics were open-ended and allowed for respondents to expand upon their experiences. With much of the current literature and media attention given to the importance of the academic experience and time demands (Haslerig, 2018; Rubin, 2016; Wolverton, 2016), it is rational that these topics are commonly discussed. Eighty-two percent of schools in this sample discussed the former, while $65 \%$ inquired about the latter. Additionally, allowing athletes to expand upon their educational and time demands experiences facilitates a deeper understanding of these areas for the athletic department, while encouraging athletes to be honest about opportunities.

Finally, athletes were asked questions about the academic support they received from two key components of their social system (Comeaux \& Harrison, 2011): head coaches and faculty. Experiences with coaches and faculty are also prominent areas of intercollegiate athletics scholarship (Engstrom et al., 1995; Horner et al, 2016; Simons et al., 2007) and scholarship continues to expand upon the ways in which these groups on campus can influence athletes. Horner and colleagues (2016) note that college athletes are most dependent upon their coaches for guidance and support, as they are key information holders in their social systems. Some athletes in their study noted that coaches used this information as a form of power to dictate and control their athletes, such as not informing them of certain academic programs or emphasizing the team performance over being socially integrated outside of sport. Still, other athletes had coaches who used information to be supportive of academics (Horner et al., 2016). Thus, while some coaches facilitated social and academic integration and commitments (Comeaux \& Harrison, 2011), others did not. Faculty also play a significant role in providing academic information and encouragement for many athletes, but research indicates that this positivity is contingent upon the nature of those interactions and other factors including the races of the faculty and athlete, the faculty's field of study, the athlete's sport, and prior experiences with members of the groups (Comeaux, 2011a). Due to the significance of athlete-coach and athlete-faculty relationships in developing athletes during college, more understanding of these dyads can be garnered from EIS if the questions are structured appropriately.

Half of the questions in these categories allowed for athletes to expand upon their experiences, and this ability to expand might be particularly important for questions pertaining to relationships with coaches and faculty as some studies have em- 
phasized the potential negative interactions athletes can have with these parties (Bell, 2009; Comeaux 2011a, 2011b). Athletic EIS should offer departing athletes more opportunities to elaborate about their experiences. While roughly $62 \%$ of academic questions did allow for athletes to expand, not offering respondents this opportunity to further discuss a topic may indicate that the athletic department does not really care about that component of the athlete's experience. For example, one institution asked its athletes to "please rate the following areas as they relate to your sport: coaches' support of academics." This was a closed-ended Likert style question that did not allow athletes to expand. Two athletes from this university rated their coach as "below average" in this category, but they were not able to offer more feedback, such as why they felt this way or how their coach could be more supportive. Because the athletes could not provide more information, the athletic department has two options: (a) do more work later to figure out why or how this coach was lacking in academic support, or (b) not do anything about the results and forego developing their coach and improving the experiences of their athletes. The former is inefficient, and the latter is negligent.

\section{Instrument \& Content Recommendations}

One major recommendation stemming from this research is that the NCAA should mandate a new policy for the creation of a uniform EIS instrument and process. For decades, scholars have tried to compare the experiences of college athletes across divisions, schools, and sports. Having a uniform EIS would assist future researchers by allowing for more in depth and accurate comparisons and analyses. As it currently stands, each athletic department creates its own EIS and can select its own athletes. This autonomy is important; it allows athletic departments to ask institution-specific questions, such as those about leadership academies or those pertaining to a certain team, such as one that experienced high coach turnover. However, this lack of uniformity makes it challenging to truly compare the experiences of athletes across institutions. The ability to cross-compare academic experiences of athletes at varying levels and/or at different institutions can ensure that equitable educational experiences are taking place across the Association. If such experiences are not occurring, new policies or programs can be put forward by those in student or athletic affairs to ensure athletes are academically engaged in their college environment while getting the most out of their athletic opportunities. Consistency in questions would make observations from FBS to FCS to Divisions I, II, and III more applicable and accurate. From there, improvements to the athlete experience can be made.

Another recommendation is to encourage athletes to complete the EIS rather than having an athletics representative fill out the form. While the representative cannot be a coach, another administrator in power can still conduct the interview, which may skew the willingness of the participants to answer honestly. Using a third neutral party, as research on EIS suggests, or having the participant fill out the form directly, can ensure honesty and integrity in the process. Additionally, certain topics are not widely discussed in the EIS in this sample, despite being prominent areas in the literature and athlete academic experience. These areas include steering and clus- 
tering to particular majors or courses and academic performance (Burke, 2017; Gayles, 2015; Sanders \& Hildenbrand, 2010). Knowing this information in conjunction with the answers to the questions about academic experiences, academic services, time demands, and coach and faculty support, would allow for a stronger instrument and better analysis of the athlete academic experience. Not inquiring further about these topics may suggest that institutions are not concerned about course and major funneling or academic performance, or that they do not want to know the answers to these questions.

Finally, institutions should abide by privacy laws, but still make their athletic EIS available to researchers. This can be done, and anonymity can be maintained. Further access is crucial to reforming and improving the academic experiences of athletes, while addressing issues of transparency in intercollegiate athletics (Knight Commission, 2010). EIS data could also be employed to suggest policy changes. In recent years, researchers and practitioners alike have proposed regulatory changes without the use of EIS, such as those that have come forward in about time demands (Wolverton, 2016) and academic reforms (Gurney et al., 2017; Lumpkin, 2017). It is likely that if these proposals included information obtained from athlete EIS, these policies could gain more support and assist in both honoring the voices of athletes and enhancing their academic experience. Additionally, such actions would make the EIS data source increasingly valuable to the intercollegiate athletics community.

\section{Athlete Experience}

\section{Overall Academic Experience}

Many of the findings from the EIS in this sample challenge the current negative light on the academic experiences of college athletes and claims of incompatibility between higher education and sports (Gurney et al., 2017; Jayakumar \& Comeaux, 2016; Knight Commission, 2010). None of the 144 athletes questioned about their overall academic experience voiced concerns over a poor experience, while $96 \%$ ( $n$ $=138$ ) expressed having a positive academic experience. One athlete noted that their academic experience was "exactly what I needed to be successful," while another mentioned they planned to graduate with two majors and two minors. When asked about their academic experience, one participant noted how thankful they were for the chance to compete in their sport while attending school: "Academically [insert institution] has given me every opportunity to succeed and discover my passion. Very grateful for all that I've learned here." The athletes' comments above reflect strong goal and institutional commitment, likely stemming from strong social and academic integration within their campus communities (Comeaux \& Harrison, 2011).

Still, a few athletes did note some academic concerns during their careers, such as issues transferring credits or finding courses that met degree requirements. Similar attitudes have been expressed by athletes in previous studies (Huml et al., 2014; Rubin \& Moses, 2017). One respondent added that they "would've liked more master's options" and wished they were challenged more academically because "some undergrad classes were a bit of a joke." Despite these less than ideal scenarios for the 
above participants, their narratives indicate a strong commitment to their goals and institution and the desire to be further integrated outside of sports. These athletes still gave their overall academic experience high marks. Thus, the majority of athletes in this sample were able to capitalize on the benefits provided by their social and academic systems to integrate into their communities and therefore find successful academic experiences.

If academics takes a backseat to athletics as some scholars assert (Hirko and Sweitzer, 2015; Huml et al., 2019), one would expect athletes to express more dissatisfaction toward their academic experiences. However, this is not what the athletes in this sample indicated. This is a significant finding because it counters the current belief held by many scholars that athletes do not have ample educational experiences. Thus, perhaps researchers and practitioners should reconsider this assumption.

\section{Time Demands}

The responses from time demands questions also counter the current narrative that athletes are over-burdened by their dual roles as students and athletes. Fourteen percent, $20 \%$, and $16 \%$ of participants noted that their time demands were excellent, good, or that they did not have issues, respectively. On the other hand, $5 \%$ of athletes found their time demands to be poor and 6\% struggled to find a balance between their schoolwork and sport. When asked what their most challenging academic experience was as an athlete, one respondent said, "balancing school and sport and coping with schoolwork on the road." Issues with travel demands that come with competing in Division I athletics are well-documented in the literature (Clotfelter, 2019; NCAA GOALS, 2016; Penn Schoen Berland, 2016; Robinson, 2017), but few athletes in this sample explicitly stated travel concerns. Additionally, few questions in the EIS addressed this topic. Future EIS could hone in on this concept and further examine this issue and the relationship it has with athletes' academic experiences as scholars have stated that these demands create challenges for college athletes, particularly regarding academic integration and success (Comeaux \& Harrison, 2011) and the quality of their overall educational experience. The positivity expressed by the athletes should be read with caution as the athletes might not know anything different, and this sample is not meant to be generalizable to the academic experiences of all college athletes.

Similarly, others noted that they eventually adjusted to the demands $(5 \%)$ or that these demands just came with being an athlete (5\%). Some examples reflecting these sentiments include: "it wasn't easy, but I made it work" and "it's a lot, but it's part of being a student-athlete." Another fairly common response was the emphasis athletes placed on learning or improving their time management, such as "if you have good time management, it's very possible to get all your work done" and "my time management was a big development." These findings support current literature noting the life skills benefits that come with participating in college athletics, along with the influence these qualities can have when it comes to applying and interviewing for jobs (Chalfin et al., 2015; Harry \& Weight, 2019; Weight, Harry, \& Navarro, 2020). In fact, research contends that experience as an athlete are viewed by potential 
employers to be just as favorable as internship experience by a non-athlete (Dwyer $\&$ Gellock, 2018). Some research even finds that former college athlete applicants are more desired by future employers than former fraternity presidents, debate team captains, or school newspaper editors (Chalfin et al., 2015).

These results support the goal, sport, and academic commitments (Comeaux \& Harrison, 2011) athletes develop when they find the ability to manage their time and get involved inside and outside of athletics. Time demands and working with athletes to find harmony between their athlete and student roles should be a continued source of focus for athletic departments and leaders. In fact, one athlete advocated for their department to provide more encouragement for athletes on their campus to get more involved in academics and other organizations outside of sports:

An idea exists among many student athletes that they don't have time for anything past their sport. I think so many people miss out on the opportunity to learn from getting involved in something within athletics or on campus where they are able to lead or organize things and people. If there were more incentives to get involved, either within athletics, in community service, or in organizations that bridge the gap between athletics and the rest of the student body, I think student athletes would really benefit. There is so much I learned from being friends with people outside my team that I've seen many of my friends miss out on by being involved only in the silo of Athletics or believing they don't have time to do anything more.

Using this athlete's voice and suggestions from others to make positive changes for athletes' academic experiences and time demands is one way athletic departments can act on the data gathered through these EIS.

\section{Coach Academic Support}

Related to time demands is the influence the coach has through supporting or not supporting athletes' educational efforts. The majority of athletes $(n=311,90 \%)$ asked about the academic support they received from their head coaches noted positive experiences. While many studies and critics have highlighted instances in which coaches emphasized athletics over academics (Jayakumar \& Comeaux, 2016; Martin et al., 2010; Singer, 2019), this did not appear to be the case for this sample of athletes. One athlete noted that their coach was "always asking about school" and that they looked to him as an example. Another athlete believed that their coach was "very respectful of time and cool with missing practice for extra credit." The actions of the coaches described above support concepts presented by Comeaux and Harrison (2011) who note that the more positive academic interactions athletes have with their coaches, the more likely they are to find academic success. Thus, the relationship and interactions athletes have with their coaches is likely to have a direct influence on their commitments, integration, and final outputs, such as graduating, attending graduate school, or transitioning out of sport (Comeaux \& Harrison, 2011; Park et al., 2013; Weight, Lewis, \& Harry, 2020). 
Despite these compliments, $8 \%$ of athletes did report that their coaches were not supportive of their academics. For example, one athlete said, "coach doesn't care about time and doesn't allow significant study time on the road." Another athlete discussed that they received a summer internship, but when they told their coach, the coach made them feel guilty for not dedicating that time to athletics. The described lower levels of coach academic support may be due to the commercialized culture of college athletics and pressures placed on coaches, such as winning at all costs and eligibility's importance over education (Comeaux \& Harrison, 2011).

Still, most athletes in this sample noted positive experiences with coach support. This is beneficial for the field of intercollegiate athletics as research shows that athletes who have positive relationships and experiences with their coaches develop increased self-efficacy, athletically and academically, which can further enhance the athlete's commitment to their sport and institution (Weight et al., 2020). Additionally, healthy coach-athlete dyads assist the athlete in adapting better to life post sport participation, an important area not expanded upon in Comeaux and Harrison's (2011) conceptual model (Jowett, 2017; Park et al., 2013). Future EIS instruments should ask athletes for more details about this support or lack thereof to facilitate continued academic development of athletes. Additionally, athletic departments should consider increased training for coaches who athletes report within their EIS to be less supportive of educational endeavors, with particular attention paid to the importance of balancing student and athlete roles and social and identity development that occurs in and outside of sport.

\section{Academic Support Programs}

Previous studies (Huml et al., 2014; Ridpath, 2010) have discussed the negative influence of academic support services for athletes. However, the sample of athletes in this study offered an opposing perspective in that they found the academic advisors and resources in their programs to be invaluable or even "life savers." Athletes voiced narratives in which their advisors went "above and beyond" or helped them "navigate the entire school system." One participant noted the positive environment they experienced: "The staff is not just about academics they also care about our wellbeing and make sure everything in our lives are going well. We can come talk to people here about anything."

These quotes demonstrate the value athletes find in the academic resources provided by their departments. Similar findings emerged in a study by Rubin and Moses (2017) who noted that athletes in focus groups discussed how vital academic support was for their continued success. Additionally, in a survey of 158 Division I athletes, research by Burns, Jasinski, Dunn, and Fletcher (2013) discovered that positive experiences in these academic support programs resulted in athletes reporting higher academic and career self-efficacy scores. The authors of this study also note that self-efficacy is related to satisfaction, and satisfaction from other research has been linked to academic success (Burns et al., 2013; Comeaux \& Harrison, 2011; Tinto, 1975). 
Scholarship on athlete experiences also notes the ways in which athlete-only services can further isolate this population from the rest of campus (Huml et al., 2014; Ridpath, 2010), however, no athlete in this study discussed feelings of isolation pertaining to athletic-academic support or facility location. Some scholars believe these services "create a subculture of low academic expectations for athletes (Comeaux, 2015, p. 275) by "hovering" or "handholding" them and focusing on eligibility over education. However, this population's role as both student and athlete and strict time demands may require additional supports in place to ensure academic success (Gayles, 2015; Jolly, 2008; Satterfield et al., 2010). A few athletes did note that they wanted more academic autonomy. When asked to describe their experience with academic counselors/coordinators, one athlete stated, "I didn't feel like I was given enough space to act as an adult," and another mentioned that their advisor was "overbearing at times, but still helpful."

Athletic EIS can be used as an avenue to examine the function of academic support services and their roles in athletes' academic experiences. Comeaux (2015) states that "anecdotes trump evidence" (p. 275) when it comes to decision-making in athlete support programs. However, through EIS, anecdotes can also turn into data utilized by practitioners in these specialized fields to continue to develop practices to assist athletes in their academic endeavors. Knowing athletes' perspectives about these resources can improve their time in college whether that is through increased support or agency. Additionally, the results of this study highlight that the academic support systems in place in this sample of institutions generally offered appropriate levels of challenge and support for their athletes, bolstering the credibility and value of these programs when it comes to fostering positive learning environments in athletes' academic systems and successful outcomes upon departure (Comeaux \& Harrison, 2011).

\section{Faculty Support}

Athletes also responded to questions about the support they received from faculty, and of those asked about this topic, $80 \%(n=128)$ had positive experiences with professors. While faculty perceptions on intercollegiate athletics and athletes are mixed (Lawrence, Hendricks, \& Ott, 2007), prominent studies in this area (Comeaux, 2011a, 2011b; Engstrom et al., 1995) highlight the tension between faculty and athletics, paying particular attention to the dumb jock stereotype that many athletes encounter. However, no athlete explicitly stated experiencing negative perceptions or being subjected to this stereotype by faculty. Many athletes noted that professors were helpful and understanding regarding their schedules and potential class conflicts. One athlete mentioned that they created "relationships with professors that will last forever" while another indicated that the professors they developed relationships with were key for assisting in the graduate school application process.

These findings bolster higher education literature noting the benefits of cultivating professor and student/athlete relationships such as cognitive development, critical thinking, social and academic integration, goals for attending professional 
school, and overall academic success (Chickering \& Gamson, 1987; Comeaux \& Harrison, 2011). To further support academic-athletic relations, increased faculty involvement in athletes' lives and the athletic decision-making processes should be considered. In a survey of Division I faculty across 23 institutions, Hendricks and colleagues (2007) discovered that $27 \%$ of faculty are dissatisfied with attention provided to athletes' education. Thus, increasing faculty engagement in these governance areas, can appease an important campus group while potentially leading to better experiences for college athletes. Indeed, despite the common misconception of faculty being anti-sport, some want to be more involved with their students and athletics (Hendricks et al., 2007). As with coach training, faculty could also receive enhanced education on how to effectively work with this unique college population in ways that both support and challenge their academic growth. With this increased understanding of college athletes, it is likely that even more athletes would report strong relationships with faculty, which would further encourage academic success and success post-graduation.

\section{Limitations \& Future Research}

A few limitations exist in this study. Access to EIS was limited to documents collected by The Intercollegiate. While the documents provide unique insight into the academic experiences of college athletes, understanding the athletes' entire academic experiences was restricted by redactions made by the institution or The Intercollegiate. Additionally, the sample size of 17 FBS institutions only represents $14 \%$ of all FBS schools. Results are also not generalizable to other levels of competition as it is likely that athletes at other institutions may have different experiences. Conducting later EIS studies within these other levels would provide interesting perspective for the field.

This study did not explore a causal relationship between athlete responses to questions regarding academic experiences, academic services, time demands, and coach and faculty support. Future studies could explore this relationship or examine questions and responses about athletes' social and athletic experiences. Due to the lack of uniformity in EIS, not all athletes in this sample faced questions that addressed all of the topics discussed in this paper. A final limitation stems from the ambiguity associated with race, ethnicity, sex, and sport affiliation of the athlete respondents. A plethora of literature notes the disparate experiences of racial majority versus minoritized athletes, along with differences between sexes and sport status. It is possible that the findings of this study also support this scholarship, but due to anonymity, this information is unknown. Despite these limitations, this study adds a unique data set and new understanding to the intercollegiate athletics literature. Through studying EIS, practitioners can not only appreciate the voices of their athletes, but also better understand their experiences and make enhancements to their educational opportunities. 


\section{References}

Benedict, J., \& Keteyian, A. (2014). The system: The glory and scandal of big-time college football. New York, NY: Anchor Books.

Branham, L. (2005). Planning to become an employer of choice. Journal of Organizational Excellence, 24(3), 57-68.

Brey, B. B. (2018). Document analysis. The SAGE Encyclopedia of Education Research, Measurement, and Evaluation. Sage Publications.

Brown, G. Document analysis as a qualitative research method. Qualitative Research Journal, 9, 27-40.

Buhler, P. M. (2011). The exit interview: A goldmine of information. Supervision, $72(8), 11-13$.

Burke, M. (2017, September 1). Report: In NCAA-mandated interviews, Syracuse athletes voiced academic advising concerns, dissatisfaction with facilities. The Daily Orange. http://dailyorange.com/2017/09/report-in-ncaa-mandated-interviews-syracuse-athletes-voiced-academic-advising-concerns-dissatisfaction-with-facilities/

Burns, G. N, Jasinski, D., Dunn, S., \& Fletcher, D. (2013). Academic support services and career decision-making self-efficacy in student athletes. The Career Development Quarterly, 61, 161-167.

Carolina Alumni Review. (2014, June 6). McCants says fraudulent classes may be all that kept him eligible. Carolina Alumni Review. Retrieved from: https://alumni. unc.edu/news/mccants-says-fraudulent-classes-may-be-all-that-kept-him-eligible/

Chalfin, P., Weight, E., Osborne, B., \& Johnson, S. (2015). The value of intercollegiate athletics participation from the perspective of employers who target athletes. Journal of Issues in Intercollegiate Athletics, 8, 1-27.

Chickering, A. W., \& Gamson, Z. F. (1987). Seven principles for good practice in undergraduate education. AAHE bulletin, 3, 2-6.

Clotfelter, C. T. (2019). Big-time sports in American universities. New York, NY: Cambridge University Press.

Comeaux, E. (2015). Innovative research into practice in support centers for college athletes: Implications for the academic progress rate initiative. Journal of College Student Development, 56(3), 274-279.

Comeaux, E. (2011a). A study of attitudes toward college student-athletes: Implications for faculty-athletics engagement. The Journal of Negro Education, 80(4), 521-532.

Comeaux, E. (2011b). Examination of faculty attitudes toward Division I college student-athletes. College Student Affairs Journal, 30(1), 75.

Comeaux, E. \& Harrison, C. K. (2011). A conceptual model of academic success for student-athletes. Educational Researcher, 40(5), 235-245.

Di Lu, L., Heinze, K. L., \& Soderstrom, S. (2018). Playing multiple positions: Student-athlete identity salience and conflict. Journal of Intercollegiate Sport, $11(2), 214-241$. 
Division I Academic Progress Rate (n.d.). NCAA. Retrieved from: http://www.ncaa. org/about/resources/research/division-i-academic-progress-rate-apr

Dwyer, B., \& Gellock, J. L. (2018). Does athletic participation signal employability?. Journal of Intercollegiate Sport, 11(1), 40-64.

Engstrom, C. M., Sedlacek, W. E., \& McEwen, M. K. (1995). Faculty attitudes toward male revenue and nonrevenue student-athletes. Journal of College Student Development, 36(3), 217-227.

Epstein, J. (2020, August 5). Texas Tech AD meets with players after report on abuse in women's basketball program. USA Today. https://www.usatoday.com/story/ sports/ncaab/big12/2020/08/05/texas-tech-ad-meets-basketball-players-afterreport-abuse/3305547001/

Exit Interviews (n.d.). The Intercollegiate. Retrieved from: https://theintercollegiate.com/exit-interviews

Faculty Oversight Committee. (2017). Faculty Oversight Committee annual report. https://www.scribd.com/document/358231143/Faculty-Oversight-Committee-Annual-Report-2017\#from embed

Gayles, J. L. (2015). Today's college athlete. In E. Comeaux (Ed.), Introduction to intercollegiate athletics, (pp. 83-91). Baltimore, MD: Johns Hopkins University Press.

Gordon, M. E. (2011). The dialectics of the exit interview: A fresh look at conversations about organizational disengagement. Management Communication Quarterly, 25(1), 59-86.

Gordon, M. E. (2014). Disclosure and deception: Communication issues in organizational disengagement. In V. D. Miller \& M. E. Gordon (Eds.), Meeting the challenge of human resource management: A communication perspective (pp. 76-87). Routledge.

Gurney, G., Lopiano, D. A., \& Zimbalist, A. (2017). Unwinding madness: What went wrong with college sports and how to fix it. Washington, DC: Brookings Institution Press.

Hargie, O. (2006). Skill in practice: An operational model of communicative performance. In O. Hargie (Ed.), Handbook of communication skills (pp. 37-70). Routledge.

Harrison, C. K., \& Boyd, J. (2007). Mainstreaming and integrating the spectacle and substance of Scholar-Baller: A new blueprint for higher education, the NCAA, and society. In D. Brooks \& R. Althouse (Eds.), Diversity and social justice in college sport: Sport management and the student-athlete (pp. 201-231). Fitness Information Technology.

Harry, M., \& Weight, E. A. (2019). Education through athletics: Interest in an athletics performance curriculum. Journal of Applied Sport Management, 11(4), $15-28$.

Haslerig, S. J. (2018). Lessons from Graduate (d) student athletes: Supporting academic autonomy and achievement. New Directions for Student Services, 163, 93-103. 
Hawkins, B., Baker, A. R., \& Brackebusch, V. B. (2015). Intercollegiate athletics and amateurism. In E. Comeaux (Ed.), Introduction to intercollegiate athletics, (pp. 312-325). Baltimore, MD: Johns Hopkins University Press.

Hendricks, S. P., \& Johnson, A. T. (2016). The athlete-student dilemma. Journal of Applied Sport Management, 8(4), 1-20.

Hermandorfer, W. D. (2014). Blown Coverage: Tackling the law's failure to protect athlete-whistleblowers. Virginia Sports \& Entertainment Law Journal, 14, 250 277.

Hirko, S., \& Sweitzer, K. V. (2015). The business model of intercollegiate sports: The haves and the have nots. In E. Comeaux (Ed.), Introduction to intercollegiate athletics, (pp. 147-162). Baltimore, MD: Johns Hopkins University Press.

Horner, M., Ternes, N., \& McLeod, C. (2016). Not going pro: On seeking lasting returns from college sports. Journal of Amateur Sport, 2(1), 188-213.

Huml, M. R., Bergman, M. J., Newell, E. M., \& Hancock, M. G. (2019). From the playing field to the classroom: The academic challenges for NCAA division I athletes. Journal for the Study of Sports and Athletes in Education, 13(2), 97115.

Huml, M. R., Hancock, M. G., \& Bergman, M. J. (2014). Additional support or extravagant cost?: Student-athletes' perceptions on athletic academic centers. Journal of Issues in Intercollegiate Athletics, 7, 410-430.

Jayakumar, U. M., \& Comeaux, E. (2016). The cultural cover-up of college athletics: How organizational culture perpetuates an unrealistic and idealized balancing act. The Journal of Higher Education, 87(4), 488-515.

Johns, R. E., \& Gorrick, J. (2016). Exploring the behavioural options of exit and voice in the exit interview process. International Journal of Employment Studies, 24(1), 25-41.

Jolly, J. C. (2008). Raising the question\# 9 is the student-athlete population unique? And why should we care?. Communication Education, 57(1), 145-151.

Jowett, S. (2017). At the heart of effective sport leadership lies the dyadic coach-athlete relationship. Sport and Exercise Psychology Review, 13(1), 62-64.

Knight Commission on Intercollegiate Athletics (2010). Restoring the balance: Dollars, values, and the future of college sports. Retrieved from: https://knightfoundation.org/wp-content/uploads/2019/06/KCIA Report restoring the balance 2011.pdf

Knight Commission on Intercollegiate Athletics. (2014). Trends in spending and institutional funding. http://spendingdatabase.knightcommission.org/fbs

Lawrence, J., Ott, M., \& Hendricks, L. (2009). Athletics reform and faculty perceptions. New Directions for Higher Education, 148, 73-81.

Lederman, D. (2019, February 1). NCAA punishes Missouri in blatant academic fraud. Inside Higher Ed. Retrieved from: https:/www.insidehighered.com/ news/2019/02/01/ncaa-punishes-missouri-blatant-case-academic-fraud 
Libit, D. (2020, August 6). How a 'clerical error' uncovered a coaching scandal at Texas Tech. Extra Points with Matt Brown. https:// extrapoints.substack.com/p/how-a-clerical-error-uncovereda?token=eyJ1c2VyX21kIjo0NzE3MzA0LCJwb3N0X21kIjo4MDE3OTEsI18iOiJya2JlWiIsImlhdCI6MTU5NjcxMTA4MSwiZXhwIjoxNTk2NzE0NjgxLCJpc3MiOiJwdWItOTA4NyIsInN1YiI6InBvc3QtcmVhY3Rpb24ifQ. nAiT93-9VUgL0gL8xzQgEYRM16nNT yhcYF11BpRi9U

Lincoln, Y., \& Guba, E. G. (1985). Naturalistic inquiry. Sage Publications.

Lofland, J., Snow, O., Anderson, L., \& Lofland, L. H. (2006). Analyzing social settings: A guide to qualitative observation and analysis. Wadsworth.

Lumpkin, A. (2017). Commercialism in college sports undermines athletes' educational opportunities and rights. In E. Comeaux (Ed.), College athletes' rights and well-being: Critical perspectives on policy and practice (pp. 101-112). Baltimore, MD: Johns Hopkins University Press.

Martin, B., Harrison, C., \& Bukstein, S. (2010). "It takes a village" for African American male scholar-athletes. Journal for the Study of Sports and Athletes in Education, 4(3), 277-295.

Merriam, S. B. (2002). Assessing and evaluating qualitative research. In S.B. Merriam (Ed.), Qualitative research in practice: Examples for discussion and analysis (pp. 18-33). Jossey- Bass.

Miles, M. B, Huberman, A. M., \& Saldana, J. M. (2020). Qualitative data analysis: A methods sourcebook. New York, NY: Sage Publications.

NCAA Goals Study (2016). NCAA GOALS Study of the student-athlete experience: Initial summary of findings. NCAA. Retrieved from: https://www.ncaa.org/sites/ default/files/GOALS 2015 summary jan2016 final 20160627.pdf

NCAA Manual (2019). NCAA. Retrieved from: https://www.ncaapublications. com/p-4577-2019-2020-ncaa-division-i-manual-august-version-available-forpresell-now.aspx

Nowell, L. S., Norris, J. M., White, D. E., \& Moules, N. J. (2017). Thematic analysis: Striving to meet the trustworthiness criteria. International journal of qualitative methods, 16(1), 1-13.

Park, S., Lavallee, D., \& Tod, D. (2013). Athletes' career transition out of sport: A systematic review. International Review of Sport and Exercise Psychology, 6(1), $22-53$.

Penn Schoen Berland. (2016). Student-athlete time demands. https://sports.cbsimg. net/images/Pac-12-Student-Athlete-Time-Demands-Obtained-by-CBS-Sports. pdf

Play Division I Sports (n.d.). NCAA. Retrieved from: http://www.ncaa.org/student-athletes/play-division-i-sports

Potuto, J. J. R., \& O'Hanlon, J. (2007). National study of student-athletes regarding their experiences as college students. College Student Journal, 41(4), 947-966.

Ridpath, B.D. (2010). Perceptions of NCAA division I athletes on motivations concerning the use of specialized academic support services in the era of academic progress rate. Journal of Issues in Intercollegiate Athletics, 3, 253-271. 
Robinson, J. A. (2017, December 11). Athletic travel and practice requirements are overwhelming students. The James G. Martin Center for Academic Renewal. Retrieved from: https:/www.jamesgmartin.center/2017/12/athletic-travel-practice-requirements-overwhelming-students/

Rubin, L. M. (2016). The detrimental effects of big-time college sports on Black student-athletes' academic success. Journal for the Study of Sports and Athletes in Education, 10(3), 185-198.

Rubin, L. M., \& Moses, R. A. (2017). Athletic subculture within student-athlete academic centers. Sociology of Sport Journal, 34(4), 317-328.

Saldana, J. M. (2016). The coding manual for qualitative researchers. New York, NY: Sage Publications.

Sanders, J. P., \& Hildenbrand, K. (2010). Major concerns? A longitudinal analysis of student-athletes' academic majors in comparative perspective. Journal of Intercollegiate Sport, 3(2), 213-233.

Satterfield, J., Croft, C., \& Godfrey, M. (2010). Whose responsibility is it anyway: the student-athlete? Academic Leadership: The Online Journal, 8(1), 34.

Schmitt, N. (2014). How staffing functions communicate to organization members and the public. In V. D. Miller \& M. E. Gordon (Eds.), Meeting the challenge of human resource management: A communication perspective (pp. 88-94). Routledge.

Shropshire, K. L., \& Williams Jr, C. D. (2017). The miseducation of the student athlete: How to fix college sports. Philadelphia, PA: Wharton School Press.

Simons, H. D., Bosworth, C., Fujita, S., \& Jensen, M. (2007). The athlete stigma in higher education. College Student Journal, 41(2), 251-274.

Singer, J. N. (2019). Race, sports, and education: Improving opportunities and outcomes for Black male college athletes. Harvard Education Press.

Singer, J. N. (2015). The miseducation of African American male college athletes. In E. Comeaux (Ed.), Introduction to intercollegiate athletes, (pp. 193-206). Baltimore, MD: Johns Hopkins University Press.

Smith, J. M., \& Willingham, M. (2015). Cheated: The UNC scandal, the education of athletes, and the future of big-time college sports. University of Nebraska Press.

Stone, J., Harrison, C. K., \& Mottley, J. (2012). "Don't call me a student-athlete": The effect of identity priming on stereotype threat for academically engaged African American college athletes. Basic \& Applied Social Psychology, 34(2), 99-106.

Tinto, V. (1975). Dropout from higher education: A theoretical synthesis of recent research. Review of educational research, 45(1), 89-125.

Weight, E. A., Harry, M., \& Navarro, K. (2020). Integrating athletics within the academy: Educational experiences of athletes, musicians, and traditional students. Journal of Issues in Intercollegiate Athletics, 13, 143-169.

Weight, E. A., Lewis, M., \& Harry, M. (2020). Self-efficacy belief and the influential coach: An examination of collegiate athletes. Journal of Athlete Development and Experience, 2(3), 198-216. 
Williams, D., Harris, C., \& Parker, J. (2008). I love you - goodbye: Exit interviews and turnover in the New Zealand hotel industry. New Zealand Journal of Employment Relations, 33(3), 70-90.

Wininger, S., \& White, T. (2008). The dumb jock stereotype: To what extent do student-athletes feel the stereotype? Journal for the Study of Sports and Athletes in Education, 2(2), 227-237.

Wolverton, B. (2016, January 8). NCAA considers easing demands on athletes' time. The Chronicle of Higher Education. Retrieved from: https://www.chronicle. com/article/NCAA-Considers-Easing-Demands/234840

Yopyk, D. J., \& Prentice, D. A. (2005). Am I an athlete or a student? Identity salience and stereotype threat in student-athletes. Basic and Applied Social Psychology, 27(4), 329-336.

Zojceska, A. (2018, December 27). Conducting effective exit interviews. TalentLyft. https://www.talentlyft.com/en/blog/article/249/the-ultimate-guide-for-conducting-effective-exit-interviews\#: : text $=\operatorname{In} \% 20$ this $\% 20$ ultimate $\% 20$ guide $\% 20$ for,culture $\% 20 \mathrm{and} \% 20$ attract $\% 20$ top $\% 20$ candidates. 